\title{
HISTÓRIA, MEMÓRIA E A EDUCAÇÃO: RELAÇÕES CONSENSUAIS E CONTRADITÓRIAS
}

\author{
Lívia Diana Rocha Magalhães ${ }^{1}$ \\ Universidade Estadual do Sudoeste da Bahia - UESB
}

\section{RESUMO}

Neste trabalho apresentamos instigações fundamentais para a discussão teórica da relação entre História, Memória e Educação, para o entendimento da apropriação de experiências passadas no presente e sua ativação dialética, dentro das razões históricas em que foram produzidas e para as quais estão sendo mantidas. Objetivamos pensar no estudo da memória como uma das fontes de expressão das relações sociais que possibilita o entendimento da educação e é dentro dessa perspectiva que passamos a estudar a memória como uma das instâncias para apreensão da história, no caso, da história da educação.

Palavras-chave: Memória; História; História da Educação.

\section{HISTORY, MEMORY AND EDUCATION: CONSENSUS RELATIONS AND CONTRADICTORY}

\begin{abstract}
We present initial instigation for theoretical discussion of the relationship between history, memory and education, for understanding the appropriation of past experience in this, his dialectic activation within the historical reasons that have been produced and for which they are being held. Think of the study of memory as a source of expression of social relations that enables understanding of education. It is within this perspective that we began to study memory as one of the instances to seizure of history, in this case, the history of education.
\end{abstract}

Keywords: Memory; History; History of Educaction.

\section{Introdução}

Sabemos que as culturas orais se utilizam, sobretudo, de técnicas de comunicação baseadas no uso da memória, para transmitir relatos construídos, poemas, descrição de personagens, situações e fatos, eventos, comemorações, etc. Como também recorrem ao uso de objetos, monumentos e lugares destinados a festas e a rituais, dentre outros recursos para perpetuar sua memória. A introdução da escrita permitiu que esses e outros registros 
da memória fossem fixados e integrados pelas palavras, em veículos e instituições especificas para a finalidade de interpreta-los a luz da teoria da história.

No século XIX, quando a História e a historiografia de corte liberal e positivista se afirmam e a "missão que se atribui aos historiadores é, pois, a de criar uma memoria coletiva que contribua a manter a coesão do Estado, e impedir que se desenvolvam outras memórias alternativas [...] frente a identidade estatal estabelecida (BARRERA, 1999, p.357) e aos sistemas públicos nacionais de educação tornar o conhecimento de história obrigatório, transformando-o em disciplina obrigatória nos currículos. Coube aos livros transmitir narrativas verossímeis sobre o fato estudado, mas, sobretudo, destacando personagens heróis da realidade. Quer dizer, educar nossa memoria social, a nossa consciência para os grandes feitos e o nacionalismo.

A historiografia marxista se encarregou de demonstrar que essa história é a história da classe dominante, desvelando as contradições da sociedade de classe. Por meio do método histórico-dialético, evidencia como os relatos construídos pela história liberal e positivista transmutam a natureza do fato, para que o enunciado seja adequado ao que é útil conhecer, reafirmando a ordem social dominante (BARRERA, 1999). Ela coloca no centro do debate relações de produção e as controvérsias ideológico-políticas que envolvem o desenvolvimento das sociedades, particularmente quando, no primeiro capítulo do Manifesto Comunista (2006), afirma que "A história de todas as sociedades que existiram até hoje tem sido a história das lutas de classes" (p.84) e abre caminho para a história social, identificada como história dos trabalhadores, das classes trabalhadoras, das classes subalternas.

Contudo, é interessante observar, que tudo o que se refere à vida das relações sociais, às tradições, aos costumes, poderíamos dizer, à memória de experiências pretéritas, que deram substrato a realidades construídas e reforçadas socialmente, passaram a ser colocadas como entrave ao desenvolvimento da história e da luta social. Por volta dos anos 80, do século XX - contrastando com a chamada história estrutural - comparece um conjunto de correntes historiográficas que se apoiam na chamada "história vinda de baixo", de homens e mulheres concretos e reais, trabalhadores e trabalhadoras etc., deslocando o debate para a chamada história problema e seus processos interpretativos. E se viu modificações notáveis e surpreendentes na produção do conhecimento histórico. Os debates historiográficos geraram novas teorias e concepções de história, as quais levaram à utilização de metodologias que potencializaram a renovação da concepção de fontes, de documentos e o questionamento ao próprio objeto da história.

Referindo-nos, sobretudo, aos estudos da educação no Brasil, diríamos que essas abordagens reverberam sobre a produção historiográfica nessa área, provocando um repertório intrigante de pesquisas que se remetem a diversas instituições, espaços e saberes educacionais, em suas muitas fragmentações e situações. As narrativas baseadas em relatos de professores, de alunos e a ordem interna da vida individual da escola, entre outros aspectos particulares, ganharam supremacia, sobretudo, por meio da história oral.

Do ponto de vista do livro didático, pelo menos no Brasil, não houve tanta repercussão. Segundo pesquisa recente, nos livros da educação básica, nos seus eixos condutores aparece:

uma perspectiva de tempo cronológica e sucessiva, definida a partir da evolução europeia. Integram-se, a partir desse epicentro, as demais culturas não europeias pelo viés cronológico. Esse é o grupo hegemônico, 
dentro do qual se insere a maior parte das coleções. [...] Tal perspectiva, ancorada em uma visão eurocêntrica do tempo e do processo histórico, acabou por se vincular, ainda que sob diferentes recortes temáticos, a uma abordagem programática marcada pela valorização da identidade nacional, por intermédio da introdução dos conteúdos de História do Brasil no início da escolarização ou, mais precisamente, a partir do segundo segmento do ensino fundamental (MIRANDA; LUCA, 2004, p. 139).

[...] Verifica-se, ainda, outro conjunto de coleções que acompanha a evolução historiográfica do pós-1960 e que procura redimensionar a ideia evolutiva e processual. Esse grupo rompe com a dimensão de tempo visto, estritamente, a partir da cronologia e multiplica as possibilidades temáticas associadas a uma historiografia Renovada — que rompe com a perspectiva tradicional e incorpora na seleção de conteúdos não só aquilo que advém da macro-renovação historiográfica do pós-1960, como também os resultados das pesquisas contemporâneas na área dos estudos históricos (MIRANDA; LUCA, 2004, p. 140).

[...] Considerando-se que a soma das duas últimas tendências não corresponde nem à metade das obras, é possível afirmar que ainda existe um enorme abismo entre a renovação historiográfica advinda da pesquisa historiográfica e o saber histórico veiculado por meio do livro didático (MIRANDA; LUCA, 2004, p. 141).

Do ponto de vista da pesquisa em educação, muitas investigações passaram a se apropriar da história oral, dando voz aos sujeitos que falam de um passado, desde o presente, conduzindo a uma correlação entre memória e história, o que nem sempre significou que as suas fontes fossem submetidas à verificação e cotejadas, ou analisadas em sua tessitura social. Como ressalva o historiador da chamada história social e da cultura Carlo Ginzburg (1989), muitos historiadores perderam a noção de prova e passaram a ver a " fonte em si mesma segundo o modo que foi constituída e não sobre aquilo do que fala" (p. 38).

O fato é que os campos da História e da História da Educação ampliam bastante a compreensão do que deve entendido como conhecimento histórico, provocando um furor epistemológico importante quando, na sua contramão, comparece, entre outras discussões, o embate entre história, história oral e memória. Não vamos entrar nesse debate, mas apenas ressaltar que, graças a essas discussões, voltou, com vigor, a reinserção de discussões clássicas sobre as conexões entre passado e presente, em sua trama estrutural.

Dentre outras, as abordagens de ascendência marxista apreendem essas novidades historiográficas sem desprezá-las, reposicionam suas análises para a relação históricodialética parte-todo. É dentro dessa perspectiva que passamos a estudar a memória como uma das instâncias para apreensão da história, no caso, da história da educação.

\section{Memória Coletiva, História e Educação}

Entre o final do século XIX e início do século XX, as fronteiras entre a sociologia e a história estão cada vez mais próximas. As duas guerras mundiais e o processo de ascensão do totalitarismo levam historiadores e sociólogos a repensarem a realidade e os fenômenos históricos em sua abordagem social. Dentre muitos estudos da memória, vamos 
nos concentrar nas abordagens do sociólogo Maurice Halbwachs. Entre 1910 e 1911, ele realizou um estudo sistemático das obras de Marx. Em 1913, na sua tese de doutorado " $A$ classe trabalhadora e seus níveis de vida" (1978) estuda a unidade da classe trabalhadora a partir de seus hábitos, costumes, gastos e necessidades. Desenvolve, dentre outros, o argumento de que as classes sociais se constituem quando adquirem consciência de sua existência. Mas, também se aproxima das ideias de Durkheim (1989), se atendo às manifestações regulares da vida social, se baseando no estudo da inercia da regularidade da vida social, das classes sociais e de suas representações.

Em sua obra "Quadros Sociais da Memória", Halbwachs (1925) vai desenvolver uma importante contribuição quando afirma que nossa Memória é Social. Se apoiando na noção durkheimiana de objetividade impessoal dos fatos sociais sobre os grupos, afirma que a memória se ancora em quadros sociais (lugares, conceitos, ideias, imagens, instituições) e que há memórias coletivas (de vários grupos) em ação, exercendo papel ativo sobre a realidade. Uma memória coletiva que é construída por grupos de pertencimentos, marcados por lugares, espaços, valores, instituições que, por sua vez, é moldada por uma dada sociedade, em uma dada época e não, necessariamente, por sua posição nas relações de produção. Vejamos em suas próprias palavras:

[...] Estos marcos colectivos de la memória no son simples formas vacias donde los recuerdos que vienen de otras partes se encajarían como en un ajuste de piezas; todo lo contrario, estos marcos son - precisamente - los instrumentos que la memoria colectiva utiliza para reconstruir un imagen del pasado acorde con cada época y en sintonía con los pensamientos dominantes de la sociedad (HALBWACHS, 2004, p. 10).

Halbwachs realiza boa parte de sua produção, principalmente, durante o conturbado processo de entre guerras mundiais, período em que se vê acuado pelo totalitarismo. Considera a História como externa aos indivíduos e a seus grupos sociais e a memória como o sustentáculo de vínculos de solidariedade múltipla, principalmente, em tempos de perseguição e de crise, como os que vivera. Concebe a memória como a história vivida por uma comunidade, suas tradições e costumes, e o conhecimento histórico como um passado morto, fato externo consumado que, só depois de objetivado, se impõe e é incorporado ao conhecimento social. Dedica atenção, em um de seus apontamentos, à distinção entre História e Memória que, posteriormente, fará parte de um dos capítulos de sua obra póstuma, Memória Coletiva.

Em que pese a sua forma de abordar História dentro da perspectiva positivista, factual, evidenciando que, para ele, história é externa a nós e, somente quando vivida de forma direta, pode ser compreendida como memória histórica, construção que ele mesmo considera imprópria e que só deve ser entendida de forma metafórica, Halbwachs deixa importante legado quando menciona que história e memória ocupam espaços distintos e, portanto, que a história não coincide, necessariamente, com a memória (ARÓSTEGUI, 2004). Inclusive, observa que, para que a experiência ou a imagem do vivido alcance a realidade do histórico, será preciso que saia de si mesma e se coloque, do ponto de vista social, como marca de uma época, se tornando de interesse coletivo.

$\mathrm{Na}$ sua visão, podemos dizer que as memórias coletivas mantêm sob controle a sociedade, por meio da sua remissão a noções construídas e operadas dentro de quadros sociais circunscritos, exercendo positividade coercitiva sobre a sociedade. Em síntese, a memória se torna um importante veículo de apreensão de um passado que não existe mais, 
mas que, todavia, permanece vivo, por intermédio de grupos sobreviventes. E ressalta que podemos guardar em nossa memória elementos sociais e culturais historicamente produzidos e acumulados pelo conhecimento histórico, de relatos construídos racionalmente, mas é na realidade social experienciada de modo vivido ou herdado, nos grupos com os quais convivemos, com os quais mantemos relações de classe, na família, nos espaços religiosos, na escola, no trabalho etc. que amparamos nossas recordações mais consistentes.

No mínimo, sua observação, dentre outros aspectos, desencadeia importantes debates sobre as fronteiras entre história vivida e a historia recebida. Como ressalta Aróstegui (2004), não podemos desconsiderar que, embora a história como a memória referem-se a realidades comuns, são distinguíveis e não são, necessariamente, coincidentes ou convergentes. Elas mantem uma relação contingente, mas não se pode descartar a confrontação conflitiva entre ambas. E nessa perspectiva, caberia perguntar por que não são coincidentes? O que há ou não de divergência nessa relação?

Ora, quando falamos da aproximação ou da distinção entre memória e história, inevitavelmente não estamos acentuando que há contradição entre a história e sua materialização concreta? De uma memória dominante versus dominada como instância ideológica, mas que também não deixa de conter as possibilidades de observação de outras manifestações dessa mesma realidade? Acreditamos que pensar os estudos da memória na perspectiva da História da Educação é reclamar o entendimento da apropriação das experiências passadas no presente, sua ativação dialética, como uma das formas, dentre outras tantas, de entendimento das estruturas econômicas, mentais, culturais e ideológicas que, inevitavelmente, entrelaçam realidade presente e passada, dentro das razões históricas em que foram produzidas e para as quais estão sendo mantidas.

Deste modo, poderíamos dizer que há confrontos e aprendizagens de memórias sociais e coletivas em disputa no processo social. Em consequência, compreendemos que pensar em memória é analisar, entre outras coisas, as instâncias do seu uso ideológico e das experiências, das situações e relações constituídas socialmente em determinados lugar e tempo, o que supõe realidades consensuais e contraditórias, dentro da dialética passado e presente. Um passado que permanece vivo, modificado, agregado a novas informações e experiências, que não se dilui, simplesmente, com o passar do tempo. Um presente que contém a síntese e os germes de informações muitas vezes dispersas, latentes, silenciadas ou controladas na sociedade, mas que operam silenciosamente ou explicitamente apropriadas pelas diversas instâncias e grupos sociais. Em outras palavras: se há diversas memórias coletivas, certamente, algumas são mantidas socialmente conforme as exigências ou necessidades de um dado presente e outras de presentes latentes que precisam ser visibilizados. Assim, sublinhamos que há

[...] muitas memórias coletivas, plurais, mantidas por interesses de seus grupos de referência social. Por sua vez, tais memórias não são lineares, se imbricam e dependem, dialeticamente, da capacidade de consciência que determinados grupos mantêm sobre seu pertencimento em uma dada formação social. Assim, deparamo-nos com o fato de que algumas memórias são constantemente ressaltadas, priorizadas, e outras relegadas, esquecidas. Este fato implica afirmar a existência de um controle do uso da memória valendo-se da necessidade de manutenção e/ou reprodução de determinadas relações sociais. (MAGALHÃES; ALMEIDA, 2011, p. 101). 
Em síntese, se ocupar da memória, significa se ocupar do presente, de como ocorre a historicidade do fenômeno de transmissão social das experiências vividas, recebidas ou herdadas, inclusive, mitificadas e como estas se movem ao longo do tempo e permanecem dialeticamente na sociedade. Resulta importante destacar, como ressaltara Marx (2008) que o presente contém a síntese mais desenvolvida do passado:

A anatomia do homem é a chave da anatomia do macaco. O que nas espécies animais inferiores indica uma forma superior, não pode, ao contrário, ser compreendida senão quando se conhece a forma superior. A economia burguesa fornece a chave da economia antiga etc. Porém, não conforme o método dos economistas, que fazem desaparecer todas as diferenças históricas e veem a forma burguesa em todas as formas de sociedade. Pode-se compreender o tributo, o dízimo, quando se compreende a renda territorial. Mas, não se deve identificá-los (MARX, 2008, p. 264).

E, desse modo, consideramos que os estudos sobre a memória social e coletiva, do ponto de vista historiográfico, não podem ser reduzidos, apenas, a uma manifestação que carrega consigo uma realidade passada. Deve-se inquirir que funções veem cumprindo e como e quando foram produzidos historicamente e como têm comparecido no presente. Especificamente no caso da educação, como a memória, como veículo de transmissão das experiências históricas vividas e recebidas, foi ou está sendo apropriada em sua tessitura social, principalmente, como elemento configurador das relações educacionais?

Nesse sentido, compreendemos que as discussões sobre memória nos remetem à análise das formas sob as quais estão balizadas as evidências da realidade, seus ocultamentos ou valorização em detrimento de determinados saberes transmitidos. E, inevitavelmente, como a história apreende esta instância de manifestação da realidade, por meio de homens e mulheres reais, produtores e produtoras de uma realidade material historicamente determinada. Como a memória social e coletiva carrega sistema de valores construído dentro das relações de produção dominante, como apreendem os conflitos e contradições sociais, podendo gerar disputas de história e de memória. Como podem ou estão provocando de forma clara ou latente, reconstruções de realidades que ficaram submersas socialmente em decorrência de usos e abusos de poder, interesses etc.

Parece-nos fundamental prestar mais atenção nos fenômenos da memória em sua historicidade dialética no presente educacional, tanto nos espaços formais, como nos informais da educação, nos apropriando das muitas fontes de informações existentes, sem desprezar nenhuma de suas manifestações, para pensarmos o passado e as dimensões teóricas e práticas de sua transmissão ou negociação social no presente, em sua dialética.

Nessa perspectiva, discutir a memória da educação pode permitir discutir a história dos grupos e da sociedade que compõem o pensar e o fazer educacional, os compartilhamentos de tempos, espaços, situações econômicas, comuns e distintas em sua dialética concreta, aludindo a problemas em sua manifestação real, tomando como centro sua transmissão, em sua dimensão fundamental de conhecimento contrastável e ideologicamente conflitivo na sociedade na qual se insere. E desta maneira, abordar as repercussões que a memória coletiva tem na construção da realidade educacional em sua dialética sincrônica e diacrônica. 
Halbwachs (2006) nos deixa uma importante contribuição quando afirma que da memória coletiva retiramos nossas aprendizagens, nossas concepções e nossos valores constitutivos e relacionais à vida social. Ensaia a distinção entre Memória e História, cunhando o conceito de memória coletiva, separando memória Social, Histórica, como uma construção selecionada, construída teoricamente e governada por um Estado Nacional. E a memórias coletivas, construídas pelos grupos sociais conviventes numa sociedade, que são assimiladas dentro de quadros sociais, materiais e morais vivenciados pelos indivíduos dentro de contextos históricos sociais constituídos por classe, por familiares, por experiências religiosas, etc. onde se constrói a memória do vivido, que nem sempre é arbitrada ou controlada pelo conhecimento histórico, mas que continua se manifestando na realidade, por meio de contextos, costumes, valores que continuam sendo recordados pelos indivíduos sociais a depender da necessidade desses grupos e do estágio da realidade que conforma as necessidades do seu presente.

E nessa perspectiva, é preciso considerar, como de certo modo induzira o próprio Halbwachs (2006), que a memória se constitui em uma importante instância de transmissão e reconstrução das experiências passadas para a manutenção de uma dada sociedade que, mesmo submetida a mudanças permanentes, depende de determinados interesses. E, muito embora Halbwachs (2006) não discuta os usos da memória e sua abordagem num quadro social de classe, ele nos oferece pistas para pensarmos sobre as abordagens e os sentidos que são dados ao passado, como estratégia analítica para o entendimento de que as memórias coletivas (dos grupos) e as de uma sociedade não mudam somente com o passar do tempo e, portanto, não podem ser analisadas fora de seus contextos de produção e recomposição material e social. Ampliando o seu pensamento para além de suas fronteiras teóricas, podemos recorrer a sua abordagem sobre memória coletiva, social e memória e história, como recurso para pensar e debate sobre temas, problemas, objetos e fontes que têm sido recuperadas e elevadas à categoria de conhecimento histórico educacional.

Sobre a construção do conhecimento histórico, propriamente dito, Juliá Santos (2007, p.4) afirma que se a "história pretende a reconstrução crítica e laica da realidade passada, buscando todos os terrenos de sua exploração, não podemos esquecer que memória passa por uma construção axiológica permanente", ou seja, pode ser manejável de acordo com as circunstâncias, podendo ser acrescentada, modificada, construída a depender se seus âmbitos de relação.

Ora, nesse ponto, também podermos dizer que o conhecimento elaborado historicamente incorpora coerências de acordo com a teoria e a visão de mundo que o historiador mobiliza para entender dada realidade. Assim, estamos ressaltando, que falar de construção do conhecimento histórico ou de reconstrução da memória coletiva e social como fonte ou objeto de estudo, significa que devemos adotar a mesma acuidade teórica e metodológica adotada na pesquisa científica. Em outras palavras, é necessário recorrer à memória como fonte de estudo da história observando-a "[...] como fonte idônea, passível de ser contratada, de contextualização temporal, relativização, objetivação e construção de um discurso metodologicamente fundamentado" (ARÓSTEGUI, 2004, p. 165). Mas, voltamos a insistir, devemos observar acuradamente que aquilo que está sendo rememorado é o passado no presente, portanto, é o crivo dado no presente que está sob júdice.

É praticamente consensual nesse debate, que a memória social e coletiva é um dos suportes da história. E aqui reside um dos interesses fundamentais de nossos estudos: a história da educação e a apreensão da memória como fonte ou objeto para o estudo das experiências educacionais, sem perder sua relação com a totalidade. A memória é, pois, Revista HISTEDBR On-line, Campinas, $n^{o}$ 67, p. 165-174,mar2016-ISSN: 1676-2584 
uma importante instância de apreensão das experiências históricas, elaboradas ou apreendidas por determinados grupos sociais e a sua consideração diacrônica e sincrônica no tempo, em sua dimensão de classe, e, portanto, conflitiva. Interessa-nos o estudo e a apreensão do fenômeno histórico educacional que processualmente tem sido recuperado, compartilhado ou destituído politicamente, em seu movimento dialético no presente.

Assim sendo e tomando como referencia a discussão da análise das perspectivas teóricas e epistemológicas da chamada história do presente, história vivida e memória, ressaltamos que ainda precisamos considerar pelos menos alguns aspectos:

a) que o processo de memorização social implica a utilização da ideologia para pensar o mundo social (BILLING, apud SANDOICA,2004), portanto na visão de mundo que os indivíduos e os grupos sociais compartilham.

b) que o presente e a memória estão conformados pelo passado, mas também pelas descobertas históricas que vão comparecendo nos processos atuais.

c) se pretendemos conhecer o presente, é preciso realizar o reconhecimento do que se quer saber sobre ele e de que perspectiva teórica e política.

d) a relação história memória e presente implica a sua compressão dialética com a totalidade social.

e) quais são as especificidades políticas das alterações entre passado e presente.

f) onde estão as manifestações da memória em sua mais diversa amplitude: documentos, monumentos e outros elementos diversos que estão indicando a presença das experiências vividas ou recebidas ao longo do tempo.

g) que acontecimentos estão sendo selecionados para fazer parte da memória social e coletiva.

h) questões de ordem metodológicas: sujeito, objeto, recorte temporal, fontes disponíveis para uso e cotejamento etc.

E assim, assinalamos que pensar as práticas e os processos sociais que compõem a relação entre histórias vividas e memórias transmitidas, que conformam fundamentalmente o que podemos chamar, na formulação de Aróstegui (2004), de "historicização da experiência" está requerendo da área da educação, mais atenção e estudos. Quando prestamos atenção ao estudo da memória, a partir do entendimento de Halbwachs (2006), observamos o que ele denominou de história vivente, ou seja, que ainda se expressa por meio de testemunhos vivos que experenciaram, direta ou indiretamente, dadas vivências ou acontecimentos conjunturais ou que atravessaram um dado processo histórico. E aqui, há de se observar a delimitação temporal da experiência ou dos acontecimentos que estão sendo estudados. Portanto, pensar em estudar a memória como recurso ou mesmo objeto de estudo, significa considerar a sua manifestação observando seu vínculo com uma dada época, com o estágio alcançado pela sociedade na qual se ancora. Daí é necessário pensar nas dificuldades e nos critérios para delimitar os fenômenos e os problemas que abarca.

Há várias denominações quanto à abordagem histórica do presente: "história recente", história do tempo presente etc. Julio Aróstegui (2004) fala em "história do tempo presente" ou "história coetânea" como as mais procedentes para designar acontecimentos que podem ser remetidos a experiências vividas e que são organizadas na memória de membros de gerações que estão vivas. Uma história experimentada frente a uma história herdada e que, inclusive, pode pertencer ao próprio estudioso, ao historiador.

Marx (1999), como citamos antes, aborda que o presente contém a síntese mais desenvolvida do passado e que, portanto, nele estão contidas as contradições sociais e ideologias que devem ser observadas, considerado a sua manifestação como entrave ou 
possibilidade para a transformação social. Se o homem é condicionado historicamente, também não mantém relação passiva com o que foi antes e com o que está dado:

A história nada mais é do que a sucessão de diferentes gerações, cada uma das quais explora os materiais, os capitais e as forças produtivas a ela transmitidas pelas gerações anteriores; ou seja, de um lado prossegue em condições completamente diferentes a atividade precedente, enquanto de outro lado, modifica as circunstâncias anteriores através de uma atividade totalmente diversa (MARX; ENGELS, 1999, p. 70).

O que estamos querendo ressaltar é que estudar o campo da memória como fonte ou objeto da história, particularmente da História da Educação, exige de nós muita acuidade, mas contém possibilidades fundamentais para o estudo das experiências educacionais que se plasmam nas memórias sociais e nas memórias coletivas de classe, de idade, gênero, etnia, em sua dialética e que conformam a realidade vivente da sociedade em seu processo histórico. E nessa perspectiva

[...] implica a consciência de que, como toda pesquisa, a investigação histórica não é desinteressada. Consequentemente, o que provoca o impulso investigativo é a necessidade de responder a alguma questão que nos interpela na realidade presente. Obviamente isso não tem a ver com o 'presentismo' nem mesmo com o 'pragmatismo'. Trata-se, antes, de própria consciência da historicidade humana, isto é, a percepção de que o presente se enraíza no passado e se projeta no futuro. Portanto, eu não posso compreender radicalmente o presente se não compreender as suas raízes, o que implica o estudo de sua gênese (SAVIANI, 2007, p.4).

Pensando a memória como objeto, fonte ou recurso para o estudo da história da educação, talvez possamos problematizar a memória social (onde está contida a memória coletiva) para o estudo da transmissão educacional nas suas diversas manifestações presentes.

\section{REFERÊNCIAS}

ARÓSTEGUI, J. La Historia vivida: sobre la historia del presente. Madri: Alianza, 2004.

BARRERA, B. J. C. Que debo recordar? Los historiadores y la configuración de la memoria. Revista Memoria y civilizacion, Espanha, 2002.

DURKHEIM, É. As formas elementares de vida religiosa. São Paulo: Edições Paulinas, 1989.

GINZBURG, C. Mitos, emblemas, indícios. Morfologia y historia. Barcelona: Gedisa, 1989.

Revista HISTEDBR On-line, Campinas, $n^{o}$ 67, p. 165-174,mar2016-ISSN: 1676-2584 
HALBWACHS, M. Las clases sociales. México: Fundo de cultura económica,1978.

.A memória coletiva. São Paulo: Centauro, 2006.

Los marcos sociales de la memoria. México: Anthropos, 2004.

MAGALHÃES, L. D.; ALMEIDA, J. R. Relações simbióticas entre Memória, História e Educação. In: História, Memória e Educação. Campinas: Alínea, 2011.

MARX, K. Contribuição à Crítica da Economia Política. São Paulo: Editora Expressão Popular, 2008.

; ENGELS, F. A Ideologia Alemã. 10. ed, São Paulo: Hucitec, 1999.

; Manifesto do Partido Comunista, 10. ed. São Paulo: Global, 2006.

MIRANDA, S. R.; LUCA, T. R. O livro didático de história hoje: um panorama a partir do PNLD. Revista Brasileira de História. São Paulo, v. 24, n. 48, 2004. Disponível em: <http://dx.doi.org/10.1590/S0102-01882004000200006>. Acesso em: mai de 2015.

SANDOICA, E. H. Tendencias historiográficas actuales. Madrid: Akal, 2004.

SANTOS, J. De nuestras memorias y de nuestras miserias. Hispania Nova - Revista de Historia Contemporánea. Madrid-Es, n. 7, 2007.

SAVIANI, Dermeval. História das Idéias Pedagógicas no Brasil. Campinas, SP: Autores Associados, 2007.

1 Docente da Universidade Estadual do Sudoeste da Bahia; doutora em Educação pela UNICAMP; coordenadora do Grupo do Museu Pedagógico/UESB e do Programa de Pós-Graduação em Memória: Linguagem e Sociedade - PPGMLS.

Recebido: fevereiro-16 $\quad$ Aprovado: março-16 